\title{
Transposon-Based Mutagenesis Generates Diverse Adeno-Associated Viral Libraries with Novel Gene Delivery Properties
}

\author{
James T. Koerber and David V. Schaffer
}

\begin{abstract}
Summary
The engineering of novel properties and functions into viral vectors for improved gene delivery remains a barrier to the development of efficient, customized gene delivery vehicles. Rational methods for designing improved viral vectors are often experimentally challenging and laborious, particularly when knowledge of viral structure-function relationships is limited. As an alternative, high-throughput libraries may be rapidly and efficiently selected for viral variants with a desired function. Here we describe a transposon-based insertional mutagenesis approach to generate large diverse adenoassociated viral (AAV) libraries containing a randomly located peptide. Briefly, a selectable marker is randomly inserted throughout the AAV2 cap gene and the resulting "bookmarked" AAV cap gene is cloned into an AAV packaging vector. The selectable marker is then replaced with a defined oligonucleotide, and the final AAV library is used to package a diverse pool of AAV virions, which can used for functional selection.
\end{abstract}

Key Words: Adeno-associated virus; transposase; mutagenesis; gene therapy; protein engineering.

\section{Introduction}

Adeno-associated viral (AAV) vectors show tremendous potential for the safe and effective treatment of a range of genetic disorders, including Alzheimer's disease, hemophilia, and Parkinson's disease (12). AAV is a non-pathogenic parvovirus with a 4.7-kb single-stranded DNA genome that contains two viral genes: rep and cap 314. While rep encodes four proteins (Rep78, Rep68, 
Rep52, and Rep40) essential for viral replication, cap encodes three structural proteins (VP1-3) that self-assemble as a 60-mer to form the viral protein shell or capsid. The extensive safety record coupled with the high efficiency of AAV vectors has furthered their use to deliver genes to various dividing and nondividing cell types in vivo (5-7). While natural evolution has generated numerous alternatives to the well-characterized and most clinically utilized AAV serotype 2 (AAV2) 8]9, numerous remaining challenges, such as a robust universal purification platform and engineering cell-specific tropism, limit the gene delivery potential of these viral vectors.

Genetic engineering has greatly extended our knowledge of AAV biology and enhanced its gene delivery properties. Site-directed mutagenesis studies have identified amino acids critical to AAV2 function (10-13), and the insertion of some peptides in defined positions in the AAV capsid, guided by sequence alignment with related parvoviruses 14]15 and crystal structures 12]16, has conferred recombinant AAV vectors with some cell-specific delivery properties. However, these rational design approaches can be laborious, and results are often highly variable, as evidenced by large differences in functional peptide display and viral infectivity for various peptides inserted into the same location (10]12). Alternative high-throughput library approaches have selected AAV vectors with novel cell-targeting peptides inserted at a defined capsid location (17/18), altered receptor binding properties (19), and the ability to evade antibody neutralization (19). However, the same insertion location is likely not optimal for displaying all functional peptide inserts, and directed evolution approaches do not typically involve the insertion of a peptide of defined function into a protein. Therefore, inserting known peptides or domains randomly throughout the entire primary amino acid sequence of the viral structural proteins may generate viral capsids with novel functions. Endonuclease methods have been used to engineer both bacterial and mammalian proteins 20!21, but such techniques fail to yield large diverse random libraries because of low DNA ligation efficiencies and biased insertions. Alternatively, transposases, enzymes capable of moving or copying DNA sequences randomly from one DNA template to another (see Fig. 1A), have greatly facilitated prokaryotic and eukaryotic evolution through random DNA insertions into an organism's genome (22). Insertional mutagenesis using such transposases has improved functional genomics studies of viral genomes 23 25), and we have recently built on this approach to identify novel peptide insertion sites within the vesicular stomatitis virus protein for retroviral and lentiviral vector engineering (26).

Transposon insertional mutagenesis relies on the transposase-facilitated transfer of a unique drug-resistance gene from a donor plasmid to a random location in an acceptor plasmid, containing the gene of interest, followed by 
A

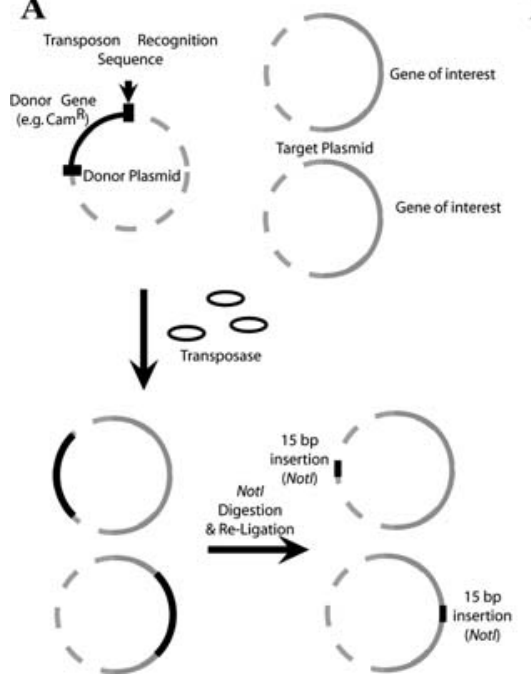

B

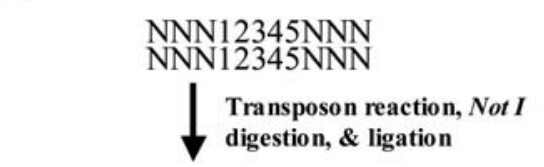

NNN12345TGCGGCCGCA12345NNN NNN12345ACGCCGGCGT12345NNN

Fig. 1. Overview of transposon-based insertional mutagenesis reaction. (A) Donor plasmid containing the donor gene (black) and acceptor plasmids containing the gene of interest (gray) are mixed in the presence of a transposase, resulting in the transfer of the donor gene from the donor to the acceptor plasmid. The resulting pool of plasmids, which contains the donor gene randomly inserted throughout the acceptor plasmid, may be digested with NotI and re-ligated to yield a plasmid library containing a "bookmark" (i.e., NotI site) ideally covering every possible internucleotide position. (B) A random 5-bp sequence in the acceptor plasmid at the insertion site is duplicated (shown in italics) and placed after the inserted NotI site (shown in bold).

subsequent selection with the appropriate antibiotics. Subsequent replacement of the drug-resistance gene with an oligonucleotide encoding a desired peptide results in a diverse plasmid library, which can be used to produce virus containing the peptide randomly located within the viral capsid. Here we present a detailed protocol for employing a transposon-based system to randomly insert an oligonucleotide encoding for a peptide of interest [i.e., a hexahistidine $\left(\mathrm{His}_{6}\right)$ tag] throughout the entire AAV2 cap gene. Other motifs to modulate cell surface binding or other viral properties can also be inserted. Therefore, this general protocol is readily extended to other peptides, AAV serotypes, and viruses to generate customized viral gene delivery vectors.

\section{Materials}

1. $2.5 \mathrm{M}$ calcium chloride $\left(\mathrm{CaCl}_{2}\right)$.

2. $2 \times$ HeBS: $1.5 \mathrm{mM} \mathrm{Na}_{2} \mathrm{HPO}_{4}, 50 \mathrm{mM}$ HEPES, $280 \mathrm{mM} \mathrm{NaCl}, \mathrm{pH} 7.10$.

3. AAV lysis buffer: $50 \mathrm{mM}$ Tris- $\mathrm{HCl}, 150 \mathrm{mM} \mathrm{NaCl}, \mathrm{pH} 8.5$. 


\section{Methods}

\subsection{Construction of $A A V$ cap Plasmid}

1. To obtain AAV cap gene from viral genomic DNA or plasmid, mix in a PCR tube: $5 \mu$ l 10× Thermopol buffer, $5 \mu$ dimethyl sulfoxide (DMSO), 1 Hl $10 \mathrm{mM}$ dNTP mix, $\sim 0.1$ pmol DNA template, 10 pmol of $5^{\prime}$ and 3' primers containing suitable restriction sites for cloning, $5 \mathrm{U}$ Vent DNA polymerase, and water to $50 \mu \mathrm{l}$. For example, to recover the AAV2 cap gene, use 5'-GCGGAAGCTTCGATCAACTACGC-3' as the 5' primer and 5'-GGGGCGCGCCGCAATTACAGATTACGAGTCAGGTATCTGGTG-3' as the $3^{\prime}$ primer. These primers introduce HindIII and AscI restriction sites (in bold), respectively, to facilitate cloning.

2. Using a QIAquick purification kit or similar spin column kit, purify the polymerase chain reaction (PCR).

3. The construction of a small plasmid vector (e.g., pBluescript) containing only the AAV cap gene ensures that more insertion events occur in the cap gene versus the vector backbone and thus reduces the final required library size, which should be significantly larger than the total number of base pairs in the template plasmid to ensure every possible position is well represented. However, the unique NotI site within pBluescript must first be eliminated because the transposon reaction introduces a NotI site. This may be accomplished by either mutagenesis or insertion of a small oligonucleotide linker at the Not I site to introduce a unique AscI site (see Note 1).

4. Digest $\sim 1 \mu \mathrm{g}$ both the 2.6-kb AAV cap PCR product and modified pBluescript plasmid with HindIII and AscI. Purify the digested products using a $\sim 1 \%$ agarose gel and a commercial gel extraction kit, such as Qiagen QIAEX II Gel Extraction Kit.

5. Ligate 75-150 fmol of AAV cap PCR product and 25 fmol of pBluescript with $5 \mathrm{U}$ of T4 DNA ligase in a $15 \mu \mathrm{l}$ reaction.

6. Transform $10 \mu \mathrm{l}$ of ligation into TOP10 bacteria and select for growth in the presence of ampicillin $(100 \mu \mathrm{g} / \mathrm{ml})$.

7. To screen for positive clones, digest plasmid DNA with HindIII and AscI. Positive clones will yield two bands: 2.6 and $3.0 \mathrm{~kb}$.

\subsection{Transposon-Based Insertion}

1. The use of commercially available transposon kits, such as the Mutation Generation System used here, permits efficient generation of a diverse library containing restriction site markers located randomly throughout the plasmid template (see Note 2).

2. To perform the transposition reaction, mix in a PCR tube: $(40 \mathrm{ng} \times$ plasmid size in kilobases) plasmid template, $4 \mu \mathrm{l} 5 \times$ reaction buffer for MuA Transposase, 1 $\mu \mathrm{l}$ Entraceposon $\left(\mathrm{M} 1-\mathrm{Cam}^{\mathrm{R}}\right.$ or $\mathrm{M} 1-\mathrm{Kan}^{\mathrm{R}}$ ) (see Note 3), $1 \mu \mathrm{l}$ MuA Transposase, and water to $20 \mu \mathrm{l}$. 
3. In a thermal cycler, incubate the reaction at $30^{\circ} \mathrm{C}$ for $1 \mathrm{~h}$, followed by a $10 \mathrm{~min}$ incubation at $75^{\circ} \mathrm{C}$. This results in either the $\mathrm{Cam}^{\mathrm{R}}$ or $\mathrm{Kan}^{\mathrm{R}}$ gene, flanked by NotI sites and with a 5 bp duplication, being randomly inserted throughout the plasmid template (see Fig. 1 and Note 4).

4. Purify the DNA mixture by ethanol precipitation through addition of $2 \mu \mathrm{l} 3 \mathrm{M}$ $\mathrm{NaOAc}, \mathrm{pH} 5.2$, and $50 \mu \mathrm{l} 100 \%$ ethanol. We recommend adding glycogen (100 $\mu \mathrm{g} / \mathrm{ml}$ final concentration) carrier as a pellet marker. Thoroughly wash the pellet with $70 \%$ ethanol and air dry. Resuspend the dried pellet in no more than $10 \mu \mathrm{l}$ water.

5. Transform the purified ligation reaction into ElectroMAX DH10B bacteria through electroporation according to the manufacturer's instructions. Take a small fraction of the electroporation reaction and streak on a bacterial agar plate with ampicillin and chloroamphenicol. Estimate the initial plasmid diversity of the library from the number of bacterial colonies. Typical initial library diversity should be on the order of $10^{6}$ independent bacterial clones.

6. Inoculate a $100 \mathrm{ml} \mathrm{TB}$ culture with the remaining reaction and shake culture at $250 \mathrm{rpm}(1.3 \times \mathrm{g})$ for $13 \mathrm{~h}$ at $37^{\circ} \mathrm{C}$ in the presence of $100 \mu \mathrm{g} / \mathrm{ml}$ ampicillin and $10 \mu \mathrm{g} / \mathrm{ml}$ chloroamphenicol.

7. Purify DNA from culture using a standard DNA purification method such as polyethylene glycol (PEG) precipitation or a commercial purification kit. Quantify purified DNA by measuring the absorbance at $260 \mathrm{~nm}$ using a UV-Vis spectrophotometer.

\subsection{Construction of AAV Plasmid Library}

1. To transfer the AAV cap gene containing the $\mathrm{Cam}^{\mathrm{R}}$ gene, digest $\sim 1 \mu \mathrm{g}$ pBS cap-Cam ${ }^{\mathrm{R}}$ and the appropriate modified AAV packing vector, such as pSub2 197 with HindIII and AscI. The pSub2 packaging vector contains the entire AAV2 genome except for the cap gene, which has been replaced with unique HindIII and NotI sites. Here, the NotI site in pSub2 has been replaced with an AscI site through mutagenesis to create pSub2Asc. Purify the digested products using a $1 \%$ agarose gel. Gel extract the 3.7-kb band from the pBS cap-Cam ${ }^{\mathrm{R}}$ sample and $5.7 \mathrm{~kb}$ linearized pSub2Asc plasmid.

2. Ligate $75-150 \mathrm{fmol}$ of $c a p-\mathrm{Cam}^{\mathrm{R}}$ fragment and $25 \mathrm{fmol}$ of pSub2Asc with $5 \mathrm{U}$ of T4 DNA ligase in a $15 \mu \mathrm{l}$ reaction (see Note $\mathbf{5}$ ).

3. Purify the ligation reaction as in step 4, Subheading $\mathbf{3 . 2}$ and transform into ElectroMAX DH10B bacteria as in step 5, Subheading 3.2. Estimate the library diversity size as in step 5, Subheading 3.2.

4. Inoculate a large-scale TB culture in the presence of ampicillin and chloroamphenicol and purify as in steps 6 and 7, Subheading 3.2. A diagnostic restriction digest screen with AgeI (which cuts near the start of the $\mathrm{Cam}^{\mathrm{R}}$ gene) and AscI (which cuts at end of cap gene) should yield a smear ranging from $\sim 1.2 \mathrm{~kb}$ to $3.8 \mathrm{~kb}$ in size.

5. To replace the chloroamphenicol-resistance gene with a desired oligonucleotide, design oligonucleotides such that the sequences at the $5^{\prime}$ and $3^{\prime}$ 
ends are compatible with NotI sites (see Fig. 13). For example, the following oligonucleotides were used for insertion of a $\mathrm{His}_{6}$ tag (histidine codons shown in bold): 5'-GGCCGGTCACCACCACCACCACCACTC-3' and 5'GGCCGAGTGGTGGTGGTGGTGGTGACC-3' (see Note 6). Mix equal amounts of single-stranded oligonucleotides in TE buffer (10 mM Tris, $1 \mathrm{mM}$ EDTA, pH 8.0) supplemented with $50 \mathrm{mM} \mathrm{NaCl}$, heat to $94^{\circ} \mathrm{C}$, and gradually cool to the anneal the oligonucleotides. Phosphorylate the resulting double-stranded oligonucleotide by mixing 300 pmol DNA, $5 \mu \mathrm{T} 4$ DNA ligase buffer, $1 \mathrm{mM}$ dATP, and 10 units T4 polynucleotide kinase. Incubate the reaction at $37^{\circ} \mathrm{C}$ for $30 \mathrm{~min}$ and inactivate the enzyme by incubation at $65^{\circ} \mathrm{C}$ for $20 \mathrm{~min}$.

6. Digest $\sim 1 \mu \mathrm{g}$ pSub2Asc cap-Cam ${ }^{\mathrm{R}}$ with NotI and gel extract the $8.3-\mathrm{kb}$ DNA fragment.

7. Ligate $75-150 \mathrm{fmol}$ of phosphorylated oligonucleotide and $25 \mathrm{fmol}$ of pSub2Asc cap fragment with $5 \mathrm{U}$ of T4 DNA ligase in a $15-\mu \mathrm{l}$ reaction. Incubate at $14{ }^{\circ} \mathrm{C}$ for at least $6 \mathrm{~h}$.

8. Purify the ligation reaction as in step 4, Subheading 3.2 and transform into ElectroMAX DH10B bacteria as in step 5, Subheading 3.2. Estimate the library diversity size as in step 5, Subheading 3.2.

9. Inoculate a large-scale $\mathrm{TB}$ culture in the presence of ampicillin and purify as in steps 6-7, Subheading 3.2. A diagnostic restriction digest screen with $E a g I$ (which cuts once in the oligo insert and once at end of the cap gene) should yield a smear ranging from $20 \mathrm{bp}$ to $2.6 \mathrm{~kb}$ in size (see Fig. 22).

\subsection{Production of Viral Library}

1. Plate $\sim 10^{7}$ HEK 293 cells in $25 \mathrm{ml}$ of DMEM onto a 15 -cm tissue culture dish such that cells are $\sim 75 \%$ confluent after $24 \mathrm{~h}$.

2. After $\sim 24 \mathrm{~h}$, transfect cells by calcium phosphate precipitation 19. Briefly, mix 7 ng pSub2Asc library, $25 \mu \mathrm{g}$ pBluescript, and $25 \mu \mathrm{g}$ pHelper with $120 \mu \mathrm{l} 2.5$

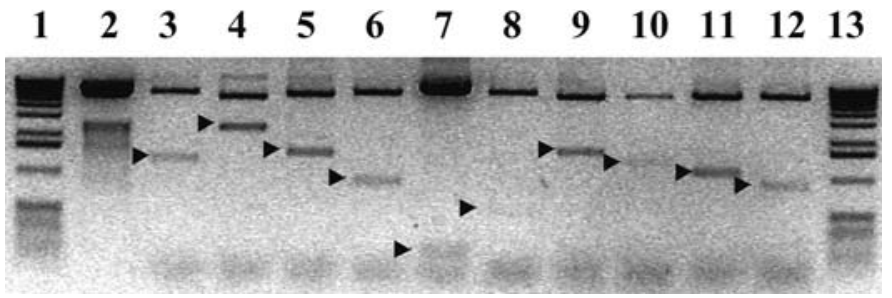

Fig. 2. Analysis of plasmid library diversity. The $\mathrm{His}_{6} \mathrm{AAV}$ insertion library and single clones contain two $\mathrm{EagI}$ sites, one that cuts once in the $\mathrm{His}_{6}$ insertion and one at $3^{\prime}$ end of the AAV cap gene. Successful insertions into cap will yield a large band ranging from 8.3 to $5.7 \mathrm{~kb}$, along with a smaller band ranging up to 2.6-kb in size (indicated by arrow). Lanes: 1, 1-kb ladder; $2, \mathrm{His}_{6}$ AAV library; 3-12, 10 randomly selected single $\mathrm{His}_{6}$ AAV clones; 13 1-kb ladder. 
$\mathrm{M} \mathrm{CaCl}_{2}$ and water to $2.5 \mathrm{ml}$ total volume. The pBluescript helps to maintain a constant DNA : calcium phosphate ratio, which we have found necessary for maintaining high efficiency DNA transfection and viral packaging. Add DNA/ $\mathrm{CaCl}_{2}$ solution dropwise to $2 \times \mathrm{HeBS}$ solution. Mix once and add mixture dropwise to cells. Remove media after 6-8 $\mathrm{h}$ and replace with $25 \mathrm{ml}$ DMEM. This 1:2 $\times 10^{-4}$ molar ratio of plasmid DNA to pSub2Asc library was calculated such that $>90 \%$ of cells received approximately one member of pSub2Asc library, assuming each cell receives $\sim 50,000$ total plasmids (27). This helps to ensure that most virions contain a viral genome with a cap gene encoding their capsid (see Note 7).

3. After $48 \mathrm{~h}$, scrape cells from the plate and centrifuge at $1000 \times g$ for $2 \mathrm{~min}$. Aspirate medium and resuspend cell pellet in $1 \mathrm{ml}$ PBS or AAV lysis buffer (50 $\mathrm{mM}$ Tris, $150 \mathrm{mM} \mathrm{NaCl}, \mathrm{pH} 8.5$ ).

4. Freeze/thaw three times using a dry ice/ethanol bath, or sonicate the cell suspension, to lyse the cells.

5. Centrifuge the lysate at $13,000 \times g$ for 10 min to clarify, or pellet cell debris. The resulting supernatant contains the AAV viral library, which can be quantified by standard protocols such as dot blotting, ELISA, or quantitative PCR. If necessary, the library can be purified by density ultracentrifugation, such as with iodixanol or $\mathrm{CsCl}$ [19. A representative titer from two independent viral productions is shown in Fig. 3A. After this stage, the viral library can be selected for variants with a desired enhanced function (see Note 8). For example, to select for the functional display of $\mathrm{His}_{6}$ tags on the viral surface, a mixture of 1 volume of cell lysate containing $\sim 10^{11}$ viral particles, 0.5 volume binding buffer $(10 \mathrm{mM}$ Tris- $\mathrm{HCl} \mathrm{pH} 8.0,300 \mathrm{mM} \mathrm{NaCl}$, and $20 \mathrm{mM}$ imidazole), and $500 \mu \mathrm{l}$ of $50 \%$
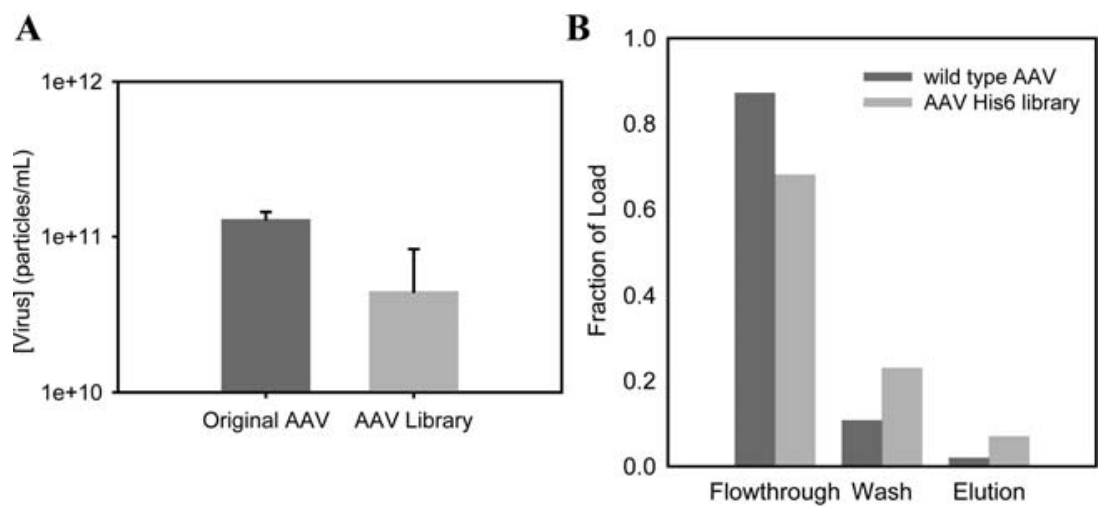

Fig. 3. Characterization of $\mathrm{His}_{6}$ AAV Library. (A) Representative titers of both wildtype AAV2 and the $\mathrm{His}_{6}$ AAV library from two independent preparations. (B) Chromatogram of viral binding fractions to Ni-NTA resin for both wildtype AAV2 and $\mathrm{His}_{6}$ AAV library. 
Ni-NTA agarose (Qiagen, Valencia, CA, USA) was agitated gently overnight at $4{ }^{\circ} \mathrm{C}$. This slurry was then loaded onto a plastic column (Kontes, Vineland, NJ, USA) before washing with $3 \mathrm{ml}$ of wash buffer $(10 \mathrm{mM}$ Tris- $\mathrm{HCl} \mathrm{pH} \mathrm{8.0,50}$ $\mathrm{mM}$ imidazole) and eluting with $3 \mathrm{ml}$ of elution buffer $(10 \mathrm{mM}$ Tris- $\mathrm{HCl} \mathrm{pH} \mathrm{8.0,}$ $500 \mathrm{mM}$ imidazole). Characterization of the binding profile of the viral library showed elevated levels of Ni-NTA binding relative to the wild type AAV2 control (see Fig. 33).

\section{Notes}

1. Alternative restriction sites may be used for the construction of this plasmid, provided the sites do not occur within the inserted drug-resistance gene or the acceptor plasmid (map provided with transposon kit).

2. Other commercial kits may result in different final insertion sizes, alternate reaction conditions, or alternate antibiotic selections. Be sure to thoroughly review the transposon kit's instructions before use.

3. Choose a drug-resistance gene that differs from gene present in the plasmid template.

4. Include a control reaction without either MuA Transposase or Entraceposon to verify the transfer of the drug-resistance gene.

5. The ratio of the amount of the plasmid insert to plasmid backbone may be varied to identify the optimal cloning condition.

6. Alternate oligonucleotides or gene fragments may be used provided the ends contain restriction sites compatible with NotI overhangs. Alternatively, the NotI overhangs may be blunted or filled in with Klenow, and the oligonucleotides may be cloned into the modified site.

7. Alternative transfection methods such as electroporation or lipofection may be used. In all cases, high transfection efficiency and proper plasmid amounts are essential for producing a diverse viral library that can be easily functionally selected.

8. For selection protocols involving infection of a cell line, such as HEK293 19, care should be taken to avoid infection with a large $(>1000)$ number of virions per cell [i.e., multiplicity of infection (MOI)]. The presence of multiple AAV genomes with different cap genes in one cell leads to potential recombination between the cap genes or production of several different versions of the VP1-3 proteins, yielding chimeric or mosaic virions 28]29. Hence, isolation of the genomes from these mosaic virions will fail to recover the genotype responsible for the novel property or phenotype.

\section{Acknowledgments}

We thank Julie $\mathrm{Yu}$ for technical assistance. This work was supported by a NSF Graduate Fellowship (to J.T.K.). UC Discovery bio 05-10559, and NIH EB003007. 


\section{References}

1. Manno, C. S., Chew, A. J., Hutchison, S., Larson, P. J., Herzog, R. W., Arruda, V. R., et al. (2003) AAV-mediated factor IX gene transfer to skeletal muscle in patients with severe hemophilia B. Blood 101, 2963-72.

2. Kay, M. A., Manno, C. S., Ragni, M. V., Larson, P. J., Couto, L. B., McClelland, A., et al. (2000) Evidence for gene transfer and expression of factor IX in haemophilia B patients treated with an AAV vector. Nat Genet 24, 257-61.

3. Fields, B. N., Knipe, D. M., Howley, P. M., and Griffin, D. E. (2001) Fields Virology, Lippincott Williams \& Wilkins, Philadelphia.

4. Srivastava, A., Lusby, E. W., and Berns, K. I. (1983) Nucleotide sequence and organization of the adeno-associated virus 2 genome. $J$ Virol 45, 555-64.

5. Flotte, T. R., Afione, S. A., Conrad, C., McGrath, S. A., Solow, R., Oka, H., et al. (1993) Stable in vivo expression of the cystic fibrosis transmembrane conductance regulator with an adeno-associated virus vector. Proc Natl Acad Sci USA 90, 10613-7.

6. Kaplitt, M. G., Leone, P., Samulski, R. J., Xiao, X., Pfaff, D. W., O’Malley, K. L., et al. (1994) Long-term gene expression and phenotypic correction using adenoassociated virus vectors in the mammalian brain. Nat Genet 8, 148-54.

7. Kaspar, B. K., Llado, J., Sherkat, N., Rothstein, J. D., and Gage, F. H. (2003) Retrograde viral delivery of IGF-1 prolongs survival in a mouse ALS model. Science 301, 839-42.

8. Gao, G., Vandenberghe, L. H., Alvira, M. R., Lu, Y., Calcedo, R., Zhou, X., et al. (2004) Clades of Adeno-associated viruses are widely disseminated in human tissues. $J$ Virol 78, 6381-8.

9. Chiorini, J. A., Kim, F., Yang, L., and Kotin, R. M. (1999) Cloning and characterization of adeno-associated virus type 5. J Virol 73, 1309-19.

10. Wu, P., Xiao, W., Conlon, T., Hughes, J., Agbandje-McKenna, M., Ferkol, T., et al. (2000) Mutational analysis of the adeno-associated virus type 2 (AAV2) capsid gene and construction of AAV2 vectors with altered tropism. $J$ Virol 74, 8635-47.

11. Rabinowitz, J. E., Xiao, W., and Samulski, R. J. (1999) Insertional mutagenesis of AAV2 capsid and the production of recombinant virus. Virology 265, 274-85.

12. Shi, W., Arnold, G. S., and Bartlett, J. S. (2001) Insertional mutagenesis of the adeno-associated virus type 2 (AAV2) capsid gene and generation of AAV2 vectors targeted to alternative cell-surface receptors. Hum Gene Ther 12, 1697-711.

13. Lochrie, M. A., Tatsuno, G. P., Christie, B., McDonnell, J. W., Zhou, S., Surosky, R., et al. (2006) Mutations on the external surfaces of adeno-associated virus type 2 capsids that affect transduction and neutralization. $J$ Virol 80, 821-34.

14. Grifman, M., Trepel, M., Speece, P., Gilbert, L. B., Arap, W., Pasqualini, R., et al. (2001) Incorporation of tumor-targeting peptides into recombinant adenoassociated virus capsids. Mol Ther 3, 964-75.

15. Girod, A., Ried, M., Wobus, C., Lahm, H., Leike, K., Kleinschmidt, J., et al. (1999) Genetic capsid modifications allow efficient re-targeting of adeno-associated virus type 2. Nat Med 5, 1052-6. 
16. Xie, Q., Bu, W., Bhatia, S., Hare, J., Somasundaram, T., Azzi, A., et al. (2002) The atomic structure of adeno-associated virus (AAV-2), a vector for human gene therapy. Proc Natl Acad Sci USA 99, 10405-10.

17. Perabo, L., Buning, H., Kofler, D. M., Ried, M. U., Girod, A., Wendtner, C. M., et al. (2003) In vitro selection of viral vectors with modified tropism: the adenoassociated virus display. Mol Ther 8, 151-7.

18. Muller, O. J., Kaul, F., Weitzman, M. D., Pasqualini, R., Arap, W., Kleinschmidt, J. A., et al. (2003) Random peptide libraries displayed on adeno-associated virus to select for targeted gene therapy vectors. Nat Biotechnol 21, 1040-6.

19. Maheshri, N., Koerber, J. T., Kaspar, B. K., and Schaffer, D. V. (2006) Directed evolution of adeno-associated virus yields enhanced gene delivery vectors. Nat Biotechnol 24, 198-204.

20. Guntas, G., and Ostermeier, M. (2004) Creation of an allosteric enzyme by domain insertion. J Mol Biol 336, 263-73.

21. Murakami, H., Hohsaka, T., and Sisido, M. (2002) Random insertion and deletion of arbitrary number of bases for codon-based random mutation of DNAs. Nat Biotechnol 20, 76-81.

22. Kazazian, H. H., Jr. (2004) Mobile elements: drivers of genome evolution. Science 303, 1626-32.

23. Brune, W., Menard, C., Hobom, U., Odenbreit, S., Messerle, M., and Koszinowski, U. H. (1999) Rapid identification of essential and nonessential herpesvirus genes by direct transposon mutagenesis. Nat Biotechnol 17, 360-4.

24. Hobom, U., Brune, W., Messerle, M., Hahn, G., and Koszinowski, U. H. (2000) Fast screening procedures for random transposon libraries of cloned herpesvirus genomes: mutational analysis of human cytomegalovirus envelope glycoprotein genes. J Virol 74, 7720-9.

25. Vilen, H., Aalto, J. M., Kassinen, A., Paulin, L., and Savilahti, H. (2003) A direct transposon insertion tool for modification and functional analysis of viral genomes. $J$ Virol 77, 123-34.

26. Yu, J. H., and Schaffer, D. V. (2006) Selection of novel vesicular stomatitis virus glycoprotein variants from a peptide insertion library for enhanced purification of retroviral and lentiviral vectors. J Virol 80, 3285-92.

27. Batard, P., Jordan, M., and Wurm, F. (2001) Transfer of high copy number plasmid into mammalian cells by calcium phosphate transfection. Gene 270, 61-8.

28. Rabinowitz, J. E., Bowles, D. E., Faust, S. M., Ledford, J. G., Cunningham, S. E., and Samulski, R. J. (2004) Cross-dressing the virion: the transcapsidation of adeno-associated virus serotypes functionally defines subgroups. J Virol 78, 4421-32.

29. Gigout, L., Rebollo, P., Clement, N., Warrington, K. H., Jr., Muzyczka, N., Linden, R. M., et al. (2005) Altering AAV tropism with mosaic viral capsids. Mol Ther 11, 856-65. 